\title{
Primary Chondrosarcoma of the Mammary Gland of a Spayed American Akita Bitch: A Case Report
}

\author{
Frank Herbert Comhaire ${ }^{1}$, Inge Matteeusen ${ }^{2}$, Hilde De Cock ${ }^{3}$ \\ ${ }^{1}$ Private Consultant, Sint Martens-Latem, Belgium \\ ${ }^{2}$ Dierenartsen Praktijk Healthy Paws, De Pinte, Belgium \\ ${ }^{3}$ MedVet Inc., Antwerpen, Belgium \\ Email: frank@comhaire.com
}

Received February 21, 2012; revised March 15, 2012; accepted April 5, 2012

\begin{abstract}
An eleven-year-old spayed American Akita bitch rapidly developed a mammary tumour which was surgically removed. The histological examination revealed the tumour to be a sarcoma that presented positive immunohistochemical staining against vimentin and protein S 100. There was no staining against pan-actin. Based on the histological aspect and the pattern of immunohistochemical staining the diagnosis of primary extraskeletal chondrosarcoma of the mammary gland was considered most probable. Two months later the patient was euthanized with recurrent local tumour and metastases in the lungs.
\end{abstract}

Keywords: Chondrosarcoma; Extraskeletal; Akita; Mammary Tumour

\section{Introduction}

Chondrosarcomas are malignant tumours characterized by the development of neoplastic chondrocytes in a fibrilary matrix. Chondrosarcomas originate from pluripotential mesenchymal cells that can differentiate into chondrocytes [1].

The overwhelming majority of chondrosarcomas occurs in bones. They are called appendicular if located in the limbs, but they also occur in flat bones such as ribs and scapulae.

The occurrence of a chondrosarcoma outside of the bones (extraskeletal) is extremely rare [2,3]. Some cases of extraskeletal primary chondrosarcomas in dogs have been described in different locations, of which the mammary gland is the most common [4].

Chondrosarcoma of the mammary gland is exceptional in clinical practice, and we could not find any published case in an Akita, either Japanese or American.

\section{Case Description}

The American Akita bitch was born on the 16th of March 2000 and was imported to Belgium from the USA in May 2000. She did not conceive in spite of several matings. She developed several pseudo pregnancies with galactorrhea and permanent gynaecomastia. On the 17th of March 2006 ovario-hysterectomy and partial resection of the mammary glands was performed (I.M), leaving only the 2 caudal glands at the right side in place, since these were normal upon palpation.
In February 2011 a mass was detected in the caudal mammary gland at the right side. This mass had developed very rapidly and did not cause any pain, general nor local symptoms. The tumour was approximately $6 \mathrm{~cm}$ in length, well defined, hard, somewhat lobular, and not adherent to the surrounding tissues or skin.

On the 14th of February 2011 the tumour was removed with radical mastectomy. Anaesthesia was applied with isofluraan inhalation, after induction with acepromazin intramuscularly, and ketamine and diazepam intravenously. A spindle shaped incision was made through the skin around the tumour into the right groin. The tumour was dissected and the surrounding tissue was removed by currettement. After closure of the subcutis with vicryl plus $2 / 0$ and the skin with ethilon 2/0, amoxicilline was injected intramuscularly, and clavaseptin (amoxicilline plus clavilanic acid, chewable tablets, $1000 \mathrm{mg} /$ day) was given orally during 5 days.

The entire mammary gland with tumour was submitted for histopathological examination (HDC). The mammary gland contained a well-defined tumour of $5.0 \times 3.0 \times 2.5$ $\mathrm{cm}$. composed of broad sheets of large, moderately pleiomorphic spindle shaped and oval cells, with large elongated nuclei containing coarse granular chromatin and a moderate amount of slightly eosinophilic cytoplasm (Figure 1). The sheets and cells were surrounded by a small amount of collagen and sometimes mucinous stroma. There were one or two mitoses per high power field (mitotic Index: 18). Rather important areas of necrosis, bleeding, 
oedema and scattered, slightly dilated ductules were also seen. Because of the atypical aspect of the tumour cells immunohistochemical staining (indirect immuno-histochemistry, Link and Label system, Dako, Heverlee, Belgium) was performed. The cells presented strong staining against vimentin (Dako, Heverlee, Belgium) and protein S 100 (Dako, Heverlee, Belgium) (Figure 2), and were negative for pan-actin (Dako, Herverlee, Belgium). Based on the morphology of the tumour and the neoplasmtic cells in combination with the immunohistochemical staining, a diagnosis was given of a high grade sarcoma, most probably a chondrosarcoma.

The dog recovered perfectly well and was free of symptoms until on the 16th of March 2011 when a rapidly growing local recurrence of the tumour was detected. Two months later the bitch started to cough. Radiography of the thorax revealed the lungs to be invaded by countless metastasis, and the dog was euthanized.

\section{Discussion}

Cancers of the mammary gland are common in the bitch.

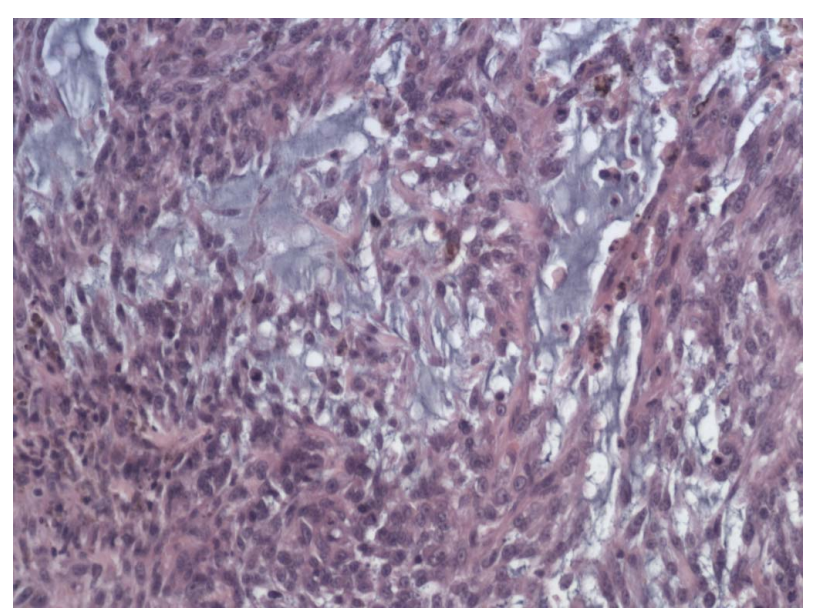

Figure 1. Haemalun-eosin stained preparation of the tumour.

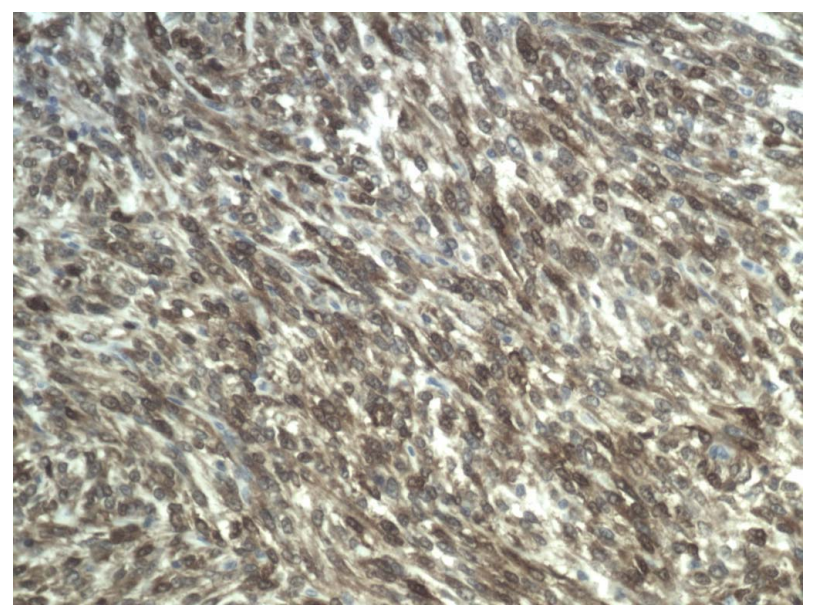

Figure 2. Immunohistochemical staining against S 100.
One can distinguish two types of tumours. First those originating from epithelial cells: the adenocarcinomas, and secondly those originating in the mesenchymal connective tissue. The latter are subdivided in sarcomas, lipomas, and mixed type [5]. Sarcomas are further subdivided into osteosarcomas, fibrosarcomas and chondrosarcomas [6]. In the veterinary literature extraskeletal chondrosarcomas constitute between $1 \%$ and $3 \%$ of all chondrosarcomas $[7,8]$. The primary extraskeletal chondrosarcomas are rapidly growing anaplastic tumours. In a retrospective study of 537 malignant tumours of the mammary glands only one case of chondrosarcoma was reported [9].

The diagnosis of chondrosarcoma can be made with certainty when cartilage tissue is present in the tumour [10]. However, this is not an absolute prerequisite, since both the histological appearance and the positive histochemical staining for protein S 100 and vimentin are considered highly suggestive for chondrosarcomas, both in dogs [11] and in humans [12-16]. Chondrosarcomas do not commonly metastasize, but local recurrence is frequent. The prognosis after radical removal of the tumour is unpredictable [17], and the survival time is highly variable [18].

In the case described here the dog survived only two months in good condition, and developed rapidly a local recurrence as well as pulmonary metastasis. This is, to the best of our knowledge, the first case of primary mammary chondrosarcoma described in an Akita.

\section{REFERENCES}

[1] B. B. Koch, L. H. Karnell, H. T. Hoffman, L. W. Apostolakis, R. A. Robinson, W. Zhen and H. R. Menck, "National Cancer Database Report on Chondrosarcoma of the Head and Neck,” Head Neck, Vol. 22, No. 4, 2000, pp. 408-425. doi:10.1002/1097-0347(200007)22:4<408::AID-HED15> 3.0.CO;2-H

[2] D. Meuten, “Tumors in Domestic Animals," Iowa State Press, Iowa, 2002, p. 788. doi:10.1002/9780470376928

[3] M. W. Woldemeskel and C. D. Grice, "Pathology in Practice. Extraskeletal Chondroblastic Osteosarcoma,” Journal of the American Veterinary Medicine Association, Vol. 238, No. 3, 2011, pp. 297-299. doi:10.2460/javma.238.3.297

[4] G. Serin and A. Aydogan, "Chondrosarcoma in the Mammary Gland of a Bitch: A Case Report,” Veterinari Medicina, Vol. 54, 2009, pp. 543-546.

[5] J. F. Hampe and W. Misdorp, “Tumors and Dysplasias of the Mammary Gland," Bulletin of the World Health Organization, Vol. 50, 1974, p. 114.

[6] S. E. Lana, G. R. Rutteman, E. G. Macewen and S. J. Withrow, "Tumors of the Mammary Gland, 357," In: S. J. Withdrow and E. G. Macewen, Eds., Small Animal Clinical Oncology, W.B. Saunders, Philadelphia, 2001, p. 
864.

[7] A. K. Patnaik, "Canine Extraskeletal Osteosarcoma and Chondrosarcoma. A Clinicopathologic Study of 14 Cases,” Veterinary Pathology, Vol. 27, No. 1, 1990, pp. 46-55. doi:10.1177/030098589002700107

[8] C. A. Popovitch, M. J. Weinstein, M. H. Goldschhmidt and F. S. Shofer, "Chondrosarcoma: A Retrospective Study of 97 Dogs (1987-1990)," Journal of the American Animal Hospital Association, Vol. 30, 1994, pp. 81-85.

[9] F. Martins, E. Tamaso and J. L. Guerra, "Retrospective Review and Systematic Study of Mammary Tumors in Dogs and Charateristics of the Extracellular Matrix," Brazilian Journal of Research Animal Science, Vol. 39, No. 1, 2002, pp. 38-42.

[10] B. R. Lee, S. H. Lee, H. Lee, H. Kim, D. Y. Kim and J. Choi, "Abdominal Aortic Chondrosarcoma in a Dog," Journal of Veterinary Medical Science, Vol. 73, No. 11, 2011, pp. 1473-1476. doi:10.1292/jvms.10-0544

[11] S. Chikata, S. Nakamura, R. Katayama, S. Yanagisawa, Y. Matsuo, I. Yamane and K. Takahashi, "Primary Chondrosarcoma in the Liver of a Dog," Veterinary Pathology Online, Vol. 43, No. 6, 2006, pp. 1033-1036. doi:10.1354/vp.43-6-1033

[12] L. Monda and M. R. Wick, "S-100 Protein Immunostaining in the Differential Diagnosis of Chondroblastoma," Human Pathology, Vol. 16, No. 3, 1985, pp. 287-292. doi:10.1016/S0046-8177(85)80016-2

[13] J. A. Regezi, R. J. Zaro, K. D. McClatchey, R. M. Courtney and J. D. Crissman, "Osteosarcomas and Chondrosarcomas of the Jaws: Immunohistochemical Correlations," Oral Surgery, Oral Medicine, Oral Pathology, Vol.
64, No. 3, 1987, pp. 302-307. doi:10.1016/0030-4220(87)90009-0

[14] T. Charo, K. Matsumoto, M. Ishizawa, S. Morimoto, S. Hukuda and H. Okabe, "Periostal Osteosarcoma and Parosteal Chondrosarcoma Evaluated by Double Immunohistochemical Staining. Report of 2 Cases," Acta Orthopedica Scandinavica, Vol. 65, No. 3, 1994, pp. 355358. doi:10.3109/17453679408995471

[15] M. P. Hoang, P. A. Suarez, L. R. Donner, J. Y. Ro, N. G. Ordnez, A. G. Ayala and B. Czemiak, "Mesenchymal Chondrosarcoma: A Small Cell Neoplasm with Polyphenotypic Differentation,” International Journal of Surgical Pathology, Vol. 8, No. 4, 2000, pp. 291-301. doi:10.1177/106689690000800408

[16] T. Kawano, J.-I. Hamada, M. Morioka, Y. Mihara, Y. Ishimaru, M. Kaku, Y. Ushio and J.-I. Kuratsu, "Skul Metastasis from Clear Cell Chondrosarcoma," Neurologia Medico-Chirurgica (Tokyo), Vol. 45, 2005, pp. 367370.

[17] J. P. Farese, J. Kirpensteijn, M. Kik, N. J. Bacon, S. S. Wattman, B. Seguin, M. Kent, J. Liptak, R. Straw, M. N. Chang, Y. Jiang and S. J. Withtow, "Biological Behavior and Clinical Outcome of 25 Dogs with Canine Appendicular Chondrosarcoma Treated by Amputation: A Veterinary Society of Surgical Oncology Retrospective Study,” Veterinary Surgery, Vol. 38, No. 8, 2009, pp. 914-919. doi:10.1111/j.1532-950X.2009.00606.X

[18] R. Casadei, M. Ricci, P. Ruggieri, R. Biagini, S. Benassi, P. Picci and M. Campanacci, "Chondrosarcoma of the Soft Tissues: Two Different Subgroups,” Journal of Bone and Joint Surgery, Vol. 73, 1991, pp. 162-168. 